University of Wollongong

Research Online

Faculty of Social Sciences - Papers (Archive) Faculty of Arts, Social Sciences \& Humanities

2015

Beyond the spectacle of suffering: Representations of rape in online antirape activism

Rachel E. Loney-Howes

University of Wollongong, rlhowes@uow.edu.au

Follow this and additional works at: https://ro.uow.edu.au/sspapers

Part of the Education Commons, and the Social and Behavioral Sciences Commons

Research Online is the open access institutional repository for the University of Wollongong. For further information contact the UOW Library: research-pubs@uow.edu.au 


\title{
Beyond the spectacle of suffering: Representations of rape in online anti-rape activism
}

\begin{abstract}
From vigilante street politics, to consciousness raising, speak outs, and now online spaces, the mediums through which representations of rape are transmitted by anti-rape activists have transformed over time. Although activists have made concerted efforts to broaden the representation of rape, narratives about women's sexual suffering and vulnerability continue to dominate popular assumptions about rape. The internet purportedly offers a more complex and networked platform for activists to engage with and challenge these representations propagated by a culture which condones sexual violence, due to a proliferation of fluid public and counter-public spaces. By examining the ways in which rape is depicted on three online anti-rape campaigns: Stop Rape Now, This is Not an Invitation to Rape Me, and Project Unbreakable, I demonstrate that online spaces do provide a viable forum for feminist anti-rape activists to contest normative depictions of rape and sexual victimisation. However, these norms are not always effectively challenged. Because of this, I argue that it is necessary to persist in questioning the modes of representation in these online anti-rape campaigns, as well as find ways to make victim-survivors theorists of their own experiences to move beyond the spectacle of sexual suffering. Otherwise, social justice struggles will continue to be beset by misrepresentation and misframing.
\end{abstract}

\section{Keywords}

suffering:, representations, rape, online, anti-rape, activism, beyond, spectacle

\section{Disciplines}

Education | Social and Behavioral Sciences

\section{Publication Details}

Loney-Howes, R. (2015). Beyond the spectacle of suffering: Representations of rape in online anti-rape activism. Outskirts: feminisms along the edge, 33 1-17. 


\section{Beyond the spectacle of suffering: representations of rape in online anti-rape activism}

\section{Rachel Loney-Howes}

From vigilante street politics, to consciousness raising, speak outs, and now online spaces, the mediums through which representations of rape are transmitted by anti-rape activists have transformed over time. Although activists have made concerted efforts to broaden the representation of rape, narratives about women's sexual suffering and vulnerability continue to dominate popular assumptions about rape. The internet purportedly offers a more complex and networked platform for activists to engage with and challenge these representations propagated by a culture which condones sexual violence, due to a proliferation of fluid public and counter-public spaces. By examining the ways in which rape is depicted on three online anti-rape campaigns: Stop Rape Now, This is Not an Invitation to Rape Me, and Project Unbreakable, I demonstrate that online spaces do provide a viable forum for feminist anti-rape activists to contest normative depictions of rape and sexual victimisation. However, these norms are not always effectively challenged. Because of this, I argue that it is necessary to persist in questioning the modes of representation in these online anti-rape campaigns, as well as find ways to make victim-survivors theorists of their own experiences to move beyond the spectacle of sexual suffering. Otherwise, social justice struggles will continue to be beset by misrepresentation and misframing.

\section{Introduction}

From vigilante street politics, to consciousness raising, speak outs, and now online spaces, the mediums through which representations of rape are transmitted by anti-rape activists have transformed over time. Historically, rape has been depicted as something feared by all women; as something that can only be legally addressed, not fought (Marcus 1992). As a result, women have been positioned as vulnerable to men's violence and powerless to stop it (Heberle 1996; Marcus 1992). Accordingly, representations of women in early anti-rape activism portrayed women as vulnerable and fearful of the possibility of being raped, or as battered, suffering women who had already been raped (Gavey 2010; Marcus 1992; Brownmiller 1986). In addition, these representations of rape were coupled with assumptions that perpetrators of rape are predominantly strangers (Estrich 1987). However, projects such as consciousness raising in the 1970 s, revealed

\section{Corresponding author:}

Rachel Loney-Howes, La Trobe University

Email: reloney-howes@students.latrobe.edu.au 
how prevalent rape and sexual violence was, as many women disclosed that they had experienced some form of sexual violence in their life time (Bevacqua 2000). Against the normative narrative, most of these rapes were committed by a partner, family member, or acquaintance, rather than a stranger in a dark alley. Nor were they necessarily violent. In the 1990 s terms such as 'date rape' and 'acquaintance rape' began to enter activist discourses that attempted to shift perceptions about who commits rape and what rape looks like (Gavey 2010). In addition, the use of rape as a tactic during armed conflict came to the forefront of international public dialogue, further broadening the discussion regarding the contexts in which rape occurs.

Yet, despite these significant conceptual shifts in the ways in which rape is represented by anti-rape activists, popular discourses about rape continue to undermine feminist efforts to challenge attitudes. Although rape is considered to be abhorrent by the vast majority of society - as Bevacqua (2000) suggests very few people would actually admit to being 'pro-rape' - myths and negative attitudes about rape persist. For example, women continue to be blamed if they are raped because of how they are dressed, the assumption that women purportedly lie about being raped remains popular, and certain women, such as married women or women of colour, are still considered 'unrapeable'. As a result, a particular 'authentic' victim-survivor subjectivity and narrative continues to dominate sociopolitical representations and assumptions about rape. These largely uniform accounts of sexual trauma, suffering, and victimisation depict the horrors and suffering experienced by rape victims, but, as a result of this focus, these depictions obscure the diverse spectrum of actual experiences and responses. A wider acceptance of this variety of experiences is needed to challenge a culture which condones rape (Heberle 1996). To address this, Buchwald et al (1993) suggest that finding platforms to speak out has the potential to affect change by putting faces to violence, and highlight the widespread experiences of rape. Alcoff and Gray (1993) however, caution this that 'speaking out' may not necessarily be socially or politically transformative in and of itself. Rather, they suggest it may reinforce the pre-theoretical narrative of sexual victimisation.

This article thus examines the ways in which online anti-rape activism has expanded the scope of for challenging the deeply entrenched myths and assumptions about rape through various modes of representation. To do so, I draw on concepts of 'counter-publics,' (Warner 2002, Fraser 1990), to highlight how the ways in which rape is represented in these online spaces challenges the boundaries of public discourses. I also utilise Sharon Marcus' (1992) concept of the gendered grammar of violence, which argues that women and men perform according to certain scripts that sustain the threat of rape, to demonstrate the extent to which these campaigns disrupt the spectacle of women's sexual suffering, vulnerability, and victimisation.

The first section of the article examines the shifts that have occurred in anti-rape activism, from vigilante street tactics to online activism. Following this I analyse 
three anti-rape campaigns - Stop Rape Now (www.stoprapenow.org), This is Not an Invitation to Rape Me (www.thisisnotaninvitationtorapeme.co.uk), and Project Unbreakable (www.project-unbreakable.org). I explore the ways in which rape and associated discourses of rape are represented in these spaces.

The article indicates that, while online spaces do provide a viable forum for feminist anti-rape activists to contest normative depictions of rape and sexual victimisation, these norms are not always effectively challenged. In this regard, questioning the representations of rape in these online spaces provides an opportunity to reflect on shifts in feminist conceptual frameworks; specifically, the extent to which these movements have sought to address problems pertaining to representation of women's sexual suffering. To overcome this issue, I suggest that online activists need to find ways to make victim-survivors of rape the theorists of their own experiences in ways that disrupt the spectacular, relativising way rape is understood in popular discourse (Alcoff and Gray 1993). Otherwise, social justice struggles will continue to be beset by misrepresentation and misframing (Fraser 2005).

\section{Anti-rape activism - from vigilante street tactics to online activism}

From the outset of the anti-rape movement, as with second wave feminism as a whole, women organised themselves at the grassroots level, starting with vigilante street tactics, creating consciousness raising groups, and organising speak outs (Bevacqua 2000). Activists endeavoured to raise awareness about the prevalence of rape, provide support to women (and men) who experienced rape, reform rape laws, and challenge the underlying social scripts inscribed in institutional structures which condoned sexual violence (Matthews 1994).

Early strategies to 'fight' rape sought to challenge gendered assumptions about women's passivity and vulnerability (Gavey 2010). Women were encouraged to learn self-defence and 'fight' back against their attackers, through which it was hoped that men would then be too afraid to rape. 'Guerrilla' activities, such as the distribution lists of known sex offenders in particular areas, was seen as a way to break the silence that protects perpetrators of sexual violence (Bevacqua 2000).

Bevacqua (2000) identifies that communications networks, both formal and informal, were instrumental in the initial spreading of the anti-rape message. These included the circulation of underground and popular feminist magazines and journals, feminist conferences, and campus activism. Such communications networks, coupled with consciousness raising resulted in a shared consciousness which sought to offer a "political reinterpretation of one's life" (Echols 1989 83). Through these consciousness raising networks, women began to erode the normative assumptions about sexual violence, and bring to light the widespread nature and experiences of "little rapes," such as verbal sexual harassment, unwanted sexual contact, to unwanted sexual advances (see Kelly 1988). What 
these networks also revealed was that sexual violence was far more likely to occur in private, not public, and to be perpetrated by a partner/husband, family member, or an acquaintance (Bevacqua 2000).

Women engaged in public forms of collective action outside of consciousness raising with marches like Take Back the Night, which attempted to highlight the need to increase women's freedom and movement in the public sphere (Bevacqua 2000). In addition, "Breaking the silence" has been ubiquitous throughout the anti-rape movement; survivor demonstrations, or "speak outs", have sought to educate society about the realities of rape and sexual violence and to reposition the problem as part of the social sphere rather than specific to the individual (Alcoff and Gray 1993 261).

The use of online spaces for anti-rape activism has become increasingly popular, with traces of earlier subversive practices (specifically consciousness raising and speak outs) being utilised. Broadly speaking, online communication channels have become significant for the proliferation of social movements, particularly those which have struggled to find a platform to speak offline (Fenton 2008; Travers 2003). Castells (2007) argues that the networked nature of the internet connects many-to-many rather than one-to-many, which traditional media platforms have historically done. This has broadened the scope of engagement with, and participation in, online activism (Fenton 2008). Given the importance of communication networks in earlier forms of anti-rape activism, as highlighted by Bevacqua (2000), it makes sense that the contemporary sites of mobilisation and discussion are situated in online spaces.

Scholarship in the field demonstrates that many women using social media and online spaces to engage in anti-rape politics do so to: detail their experiences and obtain support (Rapp et al. 2010), try to acquire some form of justice (Powell 2015), as well as seek revenge (Salter 2013). For many of these women, the use of social media to speak out about their experiences of rape and sexual violence demonstrates the limited scope of the law to recognise the diversity of rape victims and prosecute perpetrators (see Powell 2015; Rapp et al. 2010; Salter 2013). Salter (2013), in particular, shows how social media can be used to garner public support to overturn rulings, seek revenge, or shame perpetrators when they have been denied 'justice' by the law. In doing so, they demonstrate the narrow ways in which experiences of victim-survivors of rape are rendered legitimate, particularly in the courtroom (Powell 2015; Rapp et al. 2010; Salter 2013).

Salter's analysis illustrates, however, that while online communications technologies might enable everyone to speak, this does not mean that everyone is necessarily heard or taken seriously. Thus, Salter's research also highlights issues pertaining to visibility. For example, people using these spaces are seen and supported based on the ability to adhere to the conventions of a 'good' victim - typically a young, white, middle class woman, who's able to tell a convincing, coherent story. Furthermore, these acts of 'speaking out,' as described by Powell, 
Rapp et al., and Salter, reflect individual forms of activism, resistive politics, or claims for redress, rather than collective action.

While the three campaigns discussed in this article do detail individual experiences, they are collective forms of action. This follows Rentschler's (2014) analysis of the blog, Shut the Fuck up Rape Culture (stfurapeculture), which provides a space for women to tell their stories that have been denied legal and social legitimacy. The blog's moderator and other members of the community comment on these stories with messages of support as well as critical assessments of the myths circulated by rape culture, collectivising the response in an effort to mobilise resistive anti-rape politics. Such a collective response is evident in the campaigns examined in this article, all of which have an interactive function which enables people to comment, share an image of, or tell a story about themselves as part of their contribution to the movement.

\section{Subaltern counter-public spheres and women's political activism online}

The issues pertaining to visibility as identified in the work of Salter (2013), is evident in other areas of feminist activism online. Recent feminist research has identified that women's political discussions online are regularly overlooked, or deemed non-political, because they are perceived to be not engaging 'real' political discussions (Keller 2012; Shaw 2012; Harris 2008). Shaw's (2012) investigation into the feminist blogosphere, for example, highlights that 'normative' political discussions are considered to be engaged in 'genderless', politics. An informant in her study described real political deliberations to be "issues that affect the largest possible majority" or "what the mainstream media defines as daily politics" (Shaw 2012 45). Therefore, feminist politics, or issues that affect predominantly women, such as rape and sexual violence, are often ignored by popular public political deliberations.

In addition, post-colonial feminist scholars have argued that the socio-political hierarchies of women offline are perpetuated online, resulting in predominantly white women from developed countries 'speaking' and making claims in online spaces (Gajjala 2010; Friedman 2005). Yet, increasingly, scholars argue that decreasing costs and access to internet accessible technologies has shifted the landscape of voices in online social movements (Khalil 2014; Sami and Zeineb 2012). Thus, cyberspace provides women from a variety of socio-political and geographic standpoints with an unprecedented platform to engage in political discussions and establish a certain level of visibility (Travers 2003). This is not to say, though, that everyone or every campaign is equally seen and heard. Because of this, research in the field, including work examining online anti-rape activism, typically tends to suggest that such spaces are 'subaltern counter publics' (Powell 2015; Salter 2013; Shaw 2012). They are subaltern counter publics in the sense that they seek to disrupt or challenge normative public discourse (Fraser 1990). 
The online campaigns analysed in this article are counter-public in that they push against popular understandings about rape and sexual violence in, at least, a discursive sense. However, what current research investigating anti-rape activism overlooks is that the internet complicates the distinction between public and private - or public and counter-public. Michael Warner (2002) suggests that publics are fluid and dynamic, capable of manipulating the boundaries between the 'public sphere' and the 'counter-public sphere,' or the discourses which fix them as one or the other. In the context of the online sphere, I contend that the counter-publics discussed in this article have the capacity to transcend and propagate counter-public, or non-normative (feminist) political deliberations, into the public sphere. This is facilitated by the fact that these campaigns are publically accessible and are created and/or supported by public institutions. Therefore, I contend that these anti-rape campaigns are fluid counter-publics. However, as I will demonstrate, the use of particular discourses about rape can reassert normative assumptions about rape as well as perpetuate power relations and popular assumptions which determine who can speak about rape and whose experience counts. In this sense, fluid counter-publics, can help resolve issues pertaining to the representation of the spectacle of women's sexual suffering and victimisation immutably in public opinion, while others can simultaneously reinforce it. As Fraser contends, not all counter-publics are "virtuous" in the claims they make, they exist though, because they are excluded from dominant public discourses, and help facilitate a "widening of discursive contestation" (1990 67).

\section{Methodology}

A Google search using the terms 'end rape', 'not inviting rape' and 'heal rape/sexual assault' generated the following campaigns respectively. The first, Stop Rape Now, run by the United Nations Action Against Sexual Violence in Conflict (UN Action), and has had over 40,000 hits on their public service announcement videos. As noted on their website, over 1000 people have made contributions to the campaign. The second campaign, This is Not an Invitation to Rape Me, was started by Rape Crisis Scotland in 2010 and is funded by the Scottish Government. The third, Project Unbreakable, is a grassroots campaign started in 2011 by a young woman named Grace Brown that has had over 5000 submissions from all over the world. Each campaign was the first page listed in the search engine, so they were selected for their popularity and because they represent rape in distinctly different ways.

Primarily, the analysis of these websites takes a post-structural feminist approach, namely one that assesses the construction of rape through the ways in which gendered ideologies are discursively represented. In particular, I draw on the work of Sharon Marcus (1992), who utilises Butler's (1990) notion of 'gender performativity,' whereby gender is constructed and maintained through particular acts which have been coded 'masculine' or 'feminine'. Marcus argues that sociocultural and legal assumptions about rape are also constructed through a 
discursive, gendered language that renders women the objects of men's violence and subjects of fear; what she calls the gendered grammar of violence (1992 392). By this, Marcus contends that women and men perform according to scripts that sustain the threat of rape in ways that reinforce and naturalise the notion that men are powerful and sexually desiring, and women are powerless, passive sexual objects (also see Gavey 2005). These scripts, Marcus contends, can and should be disrupted. The gendered grammar of violence can also be applied to the ways in which rape during armed conflict is represented. Buss (2009), for example, draws on the gendered grammar of violence to argue that ethnic and political divisions in war crimes tribunals get remapped onto victims and perpetrators of violence, emphasising a uniform pattern of violence along historical trends. Through this, rape is considered a product of inter-ethnic conflict, not as a political, systematic tool of armed conflict underscored by gender power relations, which by extension, produces a particular narrative about authentic victims of rape and their sexual suffering (Buss 2009).

\section{Stop Rape Now}

The Stop Rape Now campaign (www.stoprapenow.org) is a United Nations initiative which seeks to bring to people's attention various examples of the use of rape during armed conflict in recent history, including Rwanda, Sierra Leone, and the Darfur region in South Sudan. Since the 1990s, the use of rape during armed conflict has come under the spotlight in international criminal and human rights law. Once considered a by-product or a spoil of war, the tribunals of Rwanda and Yugoslavia during the late 1990s and 2000s were the first to single out and prosecute rape as a weapon of war, highlighting that it often planned, deliberately carried out, and facilitated though policy measures (Buss 2009). Human rights discourse is now commonplace when discussing rape and armed conflict, and its ascension up the hierarchy of international criminal law is celebrated as a watershed moment for feminists working in the field of international policy, law, and activism (Buss 2009). So on this note, Stop Rape Now is designed to compel a global audience into action; to take rape seriously as a war crime, as a crime against humanity, and as a violation of women's human rights.

People can contribute to the campaign by posting an image of themselves with their arms crossed across their chest as a sign of solidarity. These pictures are then added to a world map and listed under the country of origin with an ' $\mathrm{X}$ ' marking the spot. Approximately 1500 images of people from around the world have been uploaded to the website, with the majority of images originating from the United States, Canada, the United Kingdom or Australia. However, there are approximately 140 countries represented on the world map spread across most continents. The campaign also draws on the socio-cultural capital of female celebrities and prominent international political figures to encourage the global public to stand in solidarity to stop rape in conflict. The campaign is thus effectively a combination of both consciousness raising and speaking out. 
Yet on the homepage of the website the victims of rape are markedly absent with only pictures of those condemning wartime rape present. The victim-survivors of rape in conflict manifest through testimonies and a video, which depicts a postconflict environment where these women had been raped. Many of the testimonies describe the affects of being repeatedly raped in front of family members or forced into sexual slavery (www.stoprapenow.org/testimonies/).

Despite having obtained a certain level of recognition within international criminal law's jurisdiction, experiences of war-time rape continue to be undermined by international law's power to determine whose experience 'counts' (Henry 2014). Buss (2009), for example, highlights how rape is less recognised as a war crime and more as a crime of genocide, meaning only particular socio-cultural groups are recognised by tribunals. She demonstrates that during the international criminal tribunal investigating the Rwandan genocide, only Tutsi women had their claims of rape as a form of genocide recognised, even though Hutu women were also raped (Buss 2009). While the Stop Rape Now campaign does not seem to single out women's experiences of rape on one side of conflict, it has been critiqued by some scholars for both denying victims the possibility of speaking out and mobilising support on their own terms (Engle 2012), and for overlooking acts of sexual violence committed by men against men during conflict (Grey and Shepherd 2013).

In addition, the campaign constructs rape as something that happens to other women through the way it creates distance between those who might experience rape and those capable of responding to it. In this way, the gendered grammar of violence is positioned along racial lines, achieved through the ways in which those who post their images as a sign of solidarity speak for, represent, or act on behalf of the victim-survivors, who appear through either their testimonies or in the video. The result is the perpetuation of particular discourses which stipulate that the 'third world woman' cannot speak for herself and is in need of rescue (see Spivak 1995). This is compounded by images on the video which reinforce the unspeakable nature of rape and the spectacular nature of their sexual suffering the victims shield their faces from the camera, appear to be crying inconsolably and remain speechless throughout, juxtaposed against predominantly western subjects standing up against the use of rape in conflict.

Such representations reinforce so-called 'third world women' as the authentic victim subjects in human rights discourses, and this homogenising of 'third world women's' (sexual) suffering and subjugation is used as impetus for global mobilisation (see Kapur 2002). This produces a one-dimensional narrative about these women's lives (Kapur 2002), obscures other harms experienced by these women, and provides them with a narrow framework through which their experiences are legitimised (Buss 2009). 


\section{This is Not an Invitation to Rape Me}

The efforts on the part of feminists to shift assumptions about rape continue to be met with opposition from what might be described as rape culture. Unlike the campaigns, Stop Rape Now and Project Unbreakable, This is Not an Invitation to Rape Me does not depict victim-survivors of rape, but rather critiques discourses associated with rape culture, which is a marked shift away from the representation of sexual suffering (www.thisisnotaninvitationtorapeme.co.uk). Specifically, the campaign seeks to subvert the ways in which dress, intimacy, drinking, and preexisting relationships underscore socio-political and legal assumptions about the possibility of rape having occurred, or its authenticity, rather than focus on the post-rape experience. In addition to the images which seek to disrupt conventions associated with rape culture, the campaign also has an interactive function where people can "have their say" about the campaign, as well as enable victim-survivors of rape to share their stories.

Although the campaign is designed to encourage people to question their own assumptions about rape, the impetus for the website was to target potential jurors in Scotland who might be sitting on rape trials (www.thisisnotaninvitationtorapeme.co.uk/the-campaign). It was also implemented to try and increase conviction rates and encourage more people to report rape to the police (www.thisisnotaninvitationtorapeme.co.uk/the-campaign). Thus the campaign, I contend, functions as a form of consciousness raising through the way it seeks to disrupt the logics of rape culture, and provide people with the opportunity to share their experiences.

The images used in the campaign are very glamorous, with the women and men both wearing fashionable clothing, and in most of the images the clothing worn by the women is provocative and revealing. In one image in particular, a young woman is wearing a t-shirt without a bra through which her nipples are visible. In another image a woman and a man are kissing and their clothes are partially removed, and there is also an image of several young women dressed up and drinking on a night out. Accompanied by the line "This is not an Invitation to Rape $\mathrm{Me}^{\prime \prime}$, the images are ironic in that they are being used to subvert normative expectations about what these images are typically associated with, namely fashion advertisements. Through this, they attempt challenge socio-cultural myths and assumptions about rape. For example, that just because a woman is dressed in a provocative way does not mean that it is an invitation to rape her; that because a woman might have an existing relationship with a man does not give him an invitation to rape her; or that just because a woman has been drinking does not mean she is to blame for being raped.

The use of humour, or irony, to challenge the phallocentric logic of rape culture is being increasingly employed in online spaces (see Kramer 2011; Rentschler 2014). Rentschler (2014) in particular identifies that online spaces use humour to help to mobilise another kind of feminist political response to rape culture by 
challenging the ways women are often deemed responsible for sexual assault. She uses the example of a hijacked Twitter site \#safetytipsforwomen, in which women posted images of themselves wearing 'rape preventative' clothing, such as chain mail or a sleeping bag, to demonstrate how the responsibilisation rhetoric in rape culture is simply a farce $(2014,70)$. Through these processes, Rentschler claims, anti-rape activists shift the responsibility back onto those who support and perpetrate it, rather than continue to perpetuate victim blaming. Some scholars have suggested that the use of irony to subvert normative patriarchal narratives can only do so on their own terms outside the masculine gaze (see Cixous et al. 1976). However, the fluid nature of these counter-public spaces highlights how effective they can be in transmitting subversive ideas into the public sphere.

What such representations, like those displayed in the campaign This is Not an Invitation to Rape Me, as well as Rentschler's example of the Twitter feed, illustrate and thus challenge, is what Gavey (2005) has described (drawing on Marcus' gendered grammar of violence) as the 'cultural scaffolding of rape'. Such a process naturalises and normalises masculine sexual desire and aggression, and feminine sexual passivity, indifference and objectification. Women exist as sexual objects to be desired over and acted upon by men, producing an unchallenged socio-political pattern of legitimised coercive heterosex which provides a smoke screen for rendering rape as 'just sex' (Gavey 2005). Through this rape scripting, men are rendered as the subjects of violence and women are the objects of that violence, perpetuating a narrow vision of what an experience of rape might entail, namely one that is violent and often committed by a stranger (Marcus 1992).

What the campaign, This is Not an Invitation to Rape Me demonstrates, is how pervasive the cultural scaffolding of rape is. Although numerous posts in the "have your say" section of the website are very supportive of the campaign - many describe how the campaign has helped them shift the blame from themselves back onto the perpetrator - there are still notable comments in support of rape culture. Thus, while the campaign is successful in highlighting rape culture as a fallacy, it is yet to be seen how effective it has been in bringing about social and legal change.

\section{Project Unbreakable}

There is a distinct history in feminist anti-rape activism of giving an account of one's experience as a way of challenging myths abound in rape culture. Unlike Stop Rape Now, which calls upon a benevolent global audience to act on behalf of victims of rape during conflict, or This is Not an Invitation to Rape Me, that challenges assumptions about what 'counts' as rape, Project Unbreakable is a campaign which enables victim-survivors to give an account of their experience. Victim-survivors of rape are invited to submit an image of themselves to the website holding a poster that contains a summary of their experience or a quote from the perpetrator of their assault. The submissions are not limited to the 
English language nor are submissions restricted to women only; men's experiences are also present on the website. However, given the gendered phenomenon of rape and sexual violence, the majority of posts are from women. The images also depict a broad age and sexuality spectrum, as well as showcase a variety of situations in which rape occurs and subjectivities of rape victimsurvivors: posts depict both younger and older adults reflecting on their experiences of childhood rape, and there are also posters which depict same-sex rape. In total, the campaign features over 5000 submissions which have been collected since 2011, and it has been featured in well-known news media outlets such as TIME magazine, The Huffington Post, and The Guardian.

Marcus contends that "the language of rape solicits women to position themselves as violable, fearful", and at the same time positions men as inherently violent and entitled to women's bodies (1992 390). Moreover, the horrors of rape are measured not in terms of the possibility of having something stolen from women but rather, the ways in which such an act renders women (as well as men) as objects to be stolen (see Marcus 1992, 399). To overcome this paradox, Buchwald et al. (1993) argue that exposure to the variety of women's experiences of rape and sexual violence in the public sphere within a culture which denies the existence of such realities would be sufficient to engender change. Their suggestion is that putting faces to, or personalising sexual violence, could persuade society to acknowledge the reality of rape and engender change.

However, Alcoff and Gray (1993) suggest that speaking out could become more like a confession rather than being a socially and politically transformative act. Moreover, Heberle (1996) argues speaking out might contribute to positioning rape as the defining moment of women's being in the world; that women can only be defined by their sexual vulnerability. She contends that such an approach fixated on the "details of survival and negotiation of (the) horror" and fear or being stolen runs the risk of perpetuating the "spectacle of women's sexual suffering" $(1996,64)$. However, many of the posters on Project Unbreakable reject the notion that they are fearful, powerless, vulnerable victims. As one particular poster states, echoed in a number of other posts: "These words have no power over me. My story and my journey is powerful and will speak louder than any word/act brought against me. I am unbreakable" (www.projectunbreakable.tumblr.com/- my emphasis). Project Unbreakable thus enables victim-survivors to become theorists of their own experiences. Through this practice, Project Unbreakable subverts the 'pre-theoretical' discourses within the spectacle of sexual suffering, such as fear, trauma, powerlessness, vulnerability and victimisation by decentring the experience of rape as the defining feature of one's life.

Moreover, the broad spectrum of experiences demonstrate the pervasive use of rape and sexual violence, and the difficulties involved in actually speaking out. Many posts describe the difficulties in convincing family members and friends that what they experienced was rape. Thus, the campaign also functions as a survivor support network, with people being able to 'like' or share posts as a sign of support 
and solidarity. In addition, Project Unbreakable has been described as an alternative form of justice because of the ways in which it provides victimsurvivors with voice, validation, and participation, which the criminal justice system, despite years of law reform efforts, continues to fail to offer victims of rape (Powell 2015).

\section{Moving beyond the spectacle of suffering - becoming a theorist of one's own experience}

The point of this article, is of course, not to position one of these online campaigns as 'better than' another, but to consider the ways in which the internet helps to facilitate the circulation of a variety of anti-rape claims, and, in turn, demonstrate some of the conceptual shifts in feminist theory and activism. It is clear from these three campaigns that there is considerable breadth regarding the variety and depth of representations of rape as well as the discourses associated with rape culture in online spaces. Moreover, there has been a significant shift away from the representation of women's sexual suffering and vulnerability.

For example, the use of the archetypal feminine subject who is raped by a stranger in a dark alley in earlier forms of activism - which reinforce notions of women as powerlessness sexual objects, of which Marcus was critical - is less common. In addition, representations of suffering and trauma are no longer prominent. This is not to suggest that victim-survivors do not experience trauma, but that trauma and suffering are not necessarily the central or sole feature of these women's lives. Project Unbreakable, in particular, seeks to subvert both these notions. Many participants from a wide variety of social subjectivities and experiences refuse to occupy the archetypal feminine victim subject status, or centralise their assault as the defining aspect of their subjectivity. In doing so, they also resist the reproduction of sexual suffering. However, they simultaneously, demonstrate how strongly the normative victim subject holds sway in socio-political and legal discourses. Particularly in regards to recognising whose experience 'counts.' Many of the victim-survivors describe the difficulties in having their experiences taken seriously by the police, and some show how the perpetrators narrative overrides the victim's when questioned by the police, as this example demonstrates: Police: "Well, we asked him and he didn't rape you, so there's nothing we can do" (http://projectunbreakable.tumblr.com/).

Conversely, This is Not an Invitation to Rape Me, depicts how scenarios normatively associated with rape culture can be powerful subversive tools, highlighting the limited ways in which rape is understood. By using images of women typically associated with commodity culture, the campaign is able to capture the viewer's attention only to challenge the viewer's reading of the image. In addition, the use of an archetypal feminine subject can also be a useful tool for manipulating the boundary between the public sphere and subaltern counterpublics. It could be argued that the website is restricted by its representation of 
white, young, middle class, heterosexual men and women. However, the use of a normative victim subject can also help to bring to the forefront the extent to which masculine sexuality, as aggressive and desiring, is privileged over feminine sexuality, which is considered to be immutably passive. As a result, the campaign exposes the 'cultural scaffolding of rape' by demonstrating the entrenched the naturalisation and normalisation of male sexual aggression and female sexual passivity. On this basis, it also highlights how these social scripts produce the conditions for rape to occur (Gavey 2005).

While these spaces depict diverse discourses of rape, highlighting the narrow lens through which rape is normatively viewed or understood, they also have the capacity to reflect what Fraser (2005) has referred to as misrepresentation. For Fraser (2005), misrepresentation describes how certain groups are denied the opportunity to participate in their own justice struggles. Misrepresentation thus perpetuates socio-political hierarchies of speaking and acting power. As I highlighted earlier, post-colonial scholars are concerned about the ways in which the internet reproduces particular hierarchies amongst women. This reproduction of offline hierarchies enables predominantly white, middle class women to make claims on behalf of 'other' women's experiences online (Friedman 2005; Gajjala 2010). Stop Rape Now, in particular, does seem to engage in misrepresentation through the way in which the victims of rape are denied their own voice and are spoken on behalf of by privileged social and political actors, for example celebrities such as Charlize Theron, Nicole Kidman, and Ban Ki-moon (Secretary General of the United Nations).

This misrepresentation is compounded by what Fraser (2005) terms misframing, whereby through misrepresentation, only certain claims are framed as legitimate, excluding experiences outside the normative discourse. In Stop Rape Now this is facilitated through the representation of suffering and trauma associated with rape in armed conflict which is conveyed as something 'unspeakable'. This leads to the construction of an 'authentic victim subject', which has the effect of homogenising 'third world women's' (sexual) suffering, by utilising their subjugation, or relative powerlessness, as impetus for global mobilisation on their behalf (see Kapur 2002). A hierarchy of rape is thus established, with the unspeakable, spectacular nature of experiences of rape during armed conflict being positioned as seemingly worse-than those which might be described as 'everyday rape' during times of peace in both developed and developing nations. Ultimately, such processes divert attention away from the broader, engrained systems of oppression that produce the conditions under which rape occurs in the first place (Henry 2014).

I do not mean to suggest that victim-survivors of rape in conflict do not suffer or experience trauma, however, campaigns like Stop Rape Now can and should incorporate survivors' claims into their activism to avoid misrepresentation and misframing. To counter this, I suggest that online campaigns, such as Stop Rape Now, find ways to make victim-survivors the theorists of their own experiences constituted by their own discourses (see Alcoff and Gray 1993). They need to 
make their voices part of the movement rather than objects on whose behalf we, the benevolent west, mobilise; to stand beside or behind instead of for. Such an approach would result in survivor-driven, or survivor-lead activism, which Mardorossian (2002) argues has been missing from the anti-rape movement since the 1980s. This would extend the boundaries of, and tools needed to engage in, political claims-making to the victim-survivors themselves. The internet has the capacity to facilitate this. Such an approach, coupled with internet communication tools helps to break down the relations of power and domination which govern who is asked to speak, and towards whom that speech is directed at. Through this, victim-survivors are able to maintain autonomy over their own narratives (see Alcoff and Gray 1993), in a similar way to which Project Unbreakable operates, and enables the campaign to move beyond the spectacle of sexual suffering.

\section{Conclusion}

The ways in which rape has been conceptually understood and represented in popular public discourses has been slow to shift, despite the efforts of feminist activists. While there have been considerable attempts to bring to light the fact that most rapes are committed by someone known to the victim, and to expose the widespread use of rape during armed conflict, myths and negative attitudes persist. This has meant that a static image or narrative about women's sexual suffering persists. However, the increased use of online campaigning has broadened the opportunities for representing and exposing a variety of experiences, challenging assumptions about rape.

Drawing on Warner's (2002) idea that publics are fluid and dynamic, renegotiating the boundaries between public and counter public, and utilising post-structural and post-colonial feminist theories, I have illustrated how the online campaigns Stop Rape Now, This is Not an Invitation to Rape Me and Project Unbreakable engage with and subvert normative assumptions about rape in order to critique public and political opinions about rape. However, I have also demonstrated how they can and do perpetuate ideas about sexual suffering and trauma. The campaigns This is Not an Invitation to Rape Me and Project Unbreakable indicate that there has been a shift away from the spectacle of suffering which capitalises on women's sexual vulnerability. The attention to the widespread use of rape during armed conflict has also been taken up in public discourses and in online spaces. However, the spectacle of suffering is utilised in representations of rape in conflict as illustrated in the discussion of the Stop Rape Now campaign.

Thus, I have argued that it is necessary to remain critical in assessments of how rape is represented, and the effect representations have on influencing public socio-cultural and legal assumptions about rape. In particular, I have suggested that, if left unchecked, campaigns can perpetuate the tensions in feminist theory and activism which result in the production of universalising assumptions about 
women's lives. This predominantly occurs due to the exclusion of victim-survivors from participating in the activism themselves, which leads to misrepresentation and misframing. To counter this, I suggest that what is needed is for online campaigns to find ways to make victim-survivors the theorists of their own experiences. However, even with such an inclusive approach, the challenge of how to translate these representations into meaningful and concrete social and legal change still remains.

\section{Acknowledgements}

Many thanks to the two anonymous reviewers, whose feedback on an earlier version of this article was invaluable. A massive thank you is also extended to Joanne Byrne, whose feedback on the redrafting of this article was very helpful. A version of this article was first presented at the Australian Women and Gender Studies Association biennial conference, in July 2014.

\section{References}

Alcoff, Linda and Gray, Laura. 1993. "Survivor Discourse: Transgression or Recuperation?" Signs no. 2(18): 260-290.

Bevacqua, Maria. 2000. Rape on the public agenda: Feminism and the politics of sexual assault. North Carolina: Northeastern University Press.

Brownmiller, Susan. 1986. Against our will: men, women, and rape. Harmondsworth: Penguin Books.

Buchwald, Emilie, Pamela R. Fletcher, and Martha Roth. 1993. Transforming a rape culture. Minneapolis, MN: Milkweed Editions.

Buss, Doris E. 2009. "Rethinking 'rape as a weapon of war'." Feminist Legal Studies no. 17 (2):145-163.

Butler, Judith. 1990. Gender trouble: feminism and the subversion of identity. New York: Routledge.

Cahill, Ann J. 2001. Rethinking rape: Cornell University Press.

Castells Manuel. 2007. "Communication, power and counter-power in the network society." International Journal of Communication no.1(1): 238-266.

Cixous, Hélène, Keith Cohen, and Paula Cohen. 1976. "The Laugh of the Medusa." Signs: Journal of Women in Culture and Society no. 1 (4):875-893.

Echols, Alice. 1989. Daring to be bad: Radical Feminism in America. Minneapolis: University of Minnesota Press.

Engle, Karen. 2012. "Celebrity diplomacy and global citizenship." Celebrity studies no. 3 (1):116-118.

Estrich, Susan. 1987. Real rape. Cambridge, Mass: Harvard University Press.

Fenton, Natalie. 2008. "Mediating solidarity." Global Media and Communication no. $4(1): 37-57$. 
Fraser, Nancy. 1990. "Rethinking the Public Sphere." Social Text no. 8 (3):56.

Fraser, Nancy. 2005. "Reframing Justice in a Globalising World." New Left Review no. 36:1-19.

Fraser, Nancy. 2008. Scales of justice: reimagining political space in a globalizing world. Malden, MA: Polity.

Friedman, Elisabeth J. 2005. "The Reality of Virtual Reality: The Internet and Gender Equality Advocacy in Latin America." Latin American Politics \& Society no. $47(3): 1-34$.

Gajjala, R; Zhang, $Y$ and Dako-Gyeke, P. 2010. "Lexicons of Women's Empowerment Online." Feminist Media Studies no. 10 (1):69-86.

Gavey, Nicola. 2010. "Figthing Rape." In Theorizing Sexual Violence, edited by Renée J. Heberle and Victoria Grace, 96-124. Hoboken: Taylor and Francis.

Gavey, Nicola. 2005. Just Sex?: The Cultural Scaffolding of Rape. London \& New York: Taylor and Francis.

Grey, Rosemary, and Laura J Shepherd. 2013. "'Stop Rape Now?" Masculinity, Responsibility, and Conflict-related Sexual Violence." Men and Masculinities no. $16(1): 115-135$.

Harris, Anita. 2008. "Young women, late modern politics, and the participatory possibilities of online cultures." Journal of Youth Studies no. 11 (5):481-495.

Heberle, Renee. 1996. "Deconstructive Strategies and the Movement against Sexual Violence." Hypatia no. 11 (4):63-76.

Henry, Nicola. 2014. "The Fixation on Wartime Rape: Feminist Critique and International Criminal Law." Social \& Legal Studies no. 23 (1):93-111.

Kapur, Ratna. 2002. "The tragedy of victimization rhetoric: resurrecting the "native" subject in international/post-colonial feminist legal politics." Harvard Human Rights Journal no. 15:1-37.

Keller, Jessalynn Marie. 2012. "Virtual feminisms: Girls' blogging communities, feminist activism, and participatory politics." Information, Communication \& Society no. 15 (3):429-19.

Kelly, Liz. 1988. Surviving Sexual Violence. Cambridge, UK: Polity Press.

Khalil, Andrea. 2014. "Tunisia's women: partners in revolution." The Journal of North African Studies no. 2 (19):186-199.

Kramer, Elise. 2011. "The playful is political: The metapragmatics of internet rapejoke arguments." Language in Society no. 40 (2):137-168.

Marcus, Sharon. 1992. "Fighting bodies, fighting words: A theory and politics of rape prevention." In Feminists theorize the political, edited by Judith Butler and Joan Wallach Scott, 385-403. New York: Routledge.

Mardorossian, Carine. 2002. "Toward a New Feminist Theory of Rape." Signs no. 3(27): 743-775.

Matthews, Nancy. 1994. Confronting Rape: the feminist anti-rape movement and the state. London: Routledge.

Powell, Anastasia. 2015. "Seeking Rape Justice: Formal and informal responses to sexual violence through technosocial counter-publics." Theoretical Criminology. Published online: 
http://sagepub.co.uk/journalsPermissions.nav.

DOI: $10.1177 / 1362480615576271$.

Project Unbreakable. (2014). "About Project Unbreakable." Accessed May 2014. http://project-unbreakable.org/.

Project Unbreakable. (2014). " Project Unbreakable: Photos." Accessed May 2014. http://projectunbreakable.tumblr.com/.

Rapp, L, Button, DM, Fleury-Steiner, B, Fleury-Steiner, R. 2010. "The Internet as a Tool for Black Feminist Activism: Lessons From an Online Antirape Protest." Feminist Criminology no. 5 (3):244-262.

Rape Crisis Scotland. 2014. "This is Not an Invitation to Rape Me." Viewed May 2014. http://www.thisisnotaninvitationtorapeme.co.uk/.

Rape Crisis Scotland. 2014. "This is Not an Invitation to Rape Me: The Campaign." Viewed May 2014. http://www.thisisnotaninvitationtorapeme.co.uk/thecampaign/.

Rape Crisis Scotland. 2014. "This is Not an Invitation to Rape Me: Have your say." Viewed May 2014. http://www.thisisnotaninvitationtorapeme.co.uk/haveyour-say/.

Rentschler, Carrie A. 2014. "Rape Culture and the Feminist Politics of Social Media." Girlhood Studies no. 7 (1):65-82.

Salter, Michael. 2013. "Justice and revenge in online counter-publics: Emerging responses to sexual violence in the age of social media." Crime, Media, Culture: An International Journal no. 9 (3):225-242.

Sami, Zlitni, and Touati Zeineb. 2012. "Social networks and women's mobilization in Tunisia." Journal of International Women's Studies no. 13 (5):46.

Shaw, Frances. 2012. "The politics of blogs: Theories of discursive activism online." Media International Australia, Incorporating Culture \& Policy (142):41-49.

Spivak, Gayatri Chakravorty. 1995. "Can the subaltern speak?" In The postcolonial studies reader, edited by Gareth Griffiths Bill Ashcroft, and Helen Tiffin, 271-313. London; New York Routledge.

Travers, Ann. 2003. "Parallel Subaltern Feminist Counterpublics in Cyberspace." Sociological Perspectives no. 46 (2):223-237.

UN Action Agaist Sexual Violence in Conflict. 2014. "Stop Rape Now." Accessed May 2014. http://www.stoprapenow.org/.

UN Action Agaist Sexual Violence in Conflict. 2014. "Stop Rape Now: Testimonies." Accessed May 2014. http://www.stoprapenow.org/testimonies/.

Warner, Michael. 2002. Publics and counterpublics. New York: Zone Books.

\section{Author biography}

Rachel is a Ph.D. candidate in Legal Studies at La Trobe University, Melbourne where she is investigating the nature, use, and scope of online spaces for antirape activism.

Email: reloney-howes@students.latrobe.edu.au 